\title{
Research on Evaluation System of Competitiveness of Power Sales Company under the Background of Electric Power Reform
}

\author{
Ningning ZHAO* \\ North China Electric Power University, No.2, Beinong \\ Road, Huilonguan, Chang-ping District, Bejing, China, \\ 102206 \\ e-mail: znn_2016@163.com \\ *Corresponding author
}

\author{
Wenzhuo WU \\ North China Electric Power University, No.2, Beinong \\ Road, Huilonguan, Chang-ping District, Bejing, China, \\ 102206 \\ e-mail: m18811357955_1@163.com
}

\begin{abstract}
The top priority of electricity reform is the sell-side reform. There are several evident benefits of it: (1)breaking the long-term monopoly situation in China's power industry (2)enhancing the competitiveness of the industry (3)optimizing resource allocation (4)reducing the cost of electricity for the whole society (5)achieving the "green, clean, efficient" concept of energy use (6)strengthening the protection of the environment. There will be five types of power sales companies in the future, and the research on their competitiveness is not only related to their future development, but also is a prerequisite for the future pattern of power market. In this paper, the fuzzy comprehensive evaluation method is used to construct the scientific and feasible evaluation index system and calculate the weights of each index, and provide some reference for the future development direction of all kinds of power sales companies.
\end{abstract}

Keywords-Power reform; Competitiveness; Power sales company; Fuzzy comprehensive evaluation method

\section{INTRODUCTION}

The addition of new power sales companies will make a huge change in the pattern of the electricity market, and its final form depends on the competitiveness of the different power sales companies in the current power market and their future development capacity. So the evaluation of the competitiveness of the five types of electricity sales company is particularly important, which won't only provide a reference of strategic plan for all types of power sales company, to some extent, but also make a prediction about the future development pattern of the electricity market.

Since the new electricity reform has just started, there are few researches on assessment of the competitiveness of the power sale companies for a reference. This paper has further explored and established a more scientific and feasible evaluation mechanism on the basis of literature [1] and literature [2].Literature [1] describes the evaluation model of the competitiveness of the power sales company and literature [2] describes the principles and methods about how to construct the evaluation index system. This paper has a real reference value in the practical operation level.

\section{THE STEPS OF COMPETITIVE EVALUATION}

(1)Comprehensive macro and micro environment in various factors, and establish a scientific, specific and clear evaluation index system.

(2)Clarify the index value, quantify the qualitative indicators, and make the quantitative indicators normative and standard.

(3)Calculate the weight of each index and verify the scientific for evaluation.

(4)Use the evaluation index system to evaluate each type of the power sales company, obtain the competitiveness evaluation score, and analyze it.

\section{CONSTRUCTION OF EVALUATION INDEX SYSTEM OF COMPETITIVENESS}

The opening of the electricity market not only provides opportunities for social capital to enter the electricity market, but also stimulates the power users to pursue the personalized service. In the future, if the power sales companies want to strive for more users, they shouldn't just focus on the management of enterprise resources and deployment, but should pay more attention to customer needs and to the demand side response for the purpose of establishing long-term trust and long-term cooperation with customers. That means the power sales company should do well the original business (Business Expansion Report Forms Setting, Metering, Billing, Information Consulting), at the same time, should actively carry out electric power marketing and demand-side management. For example, make an active exploration in the energy-saving services, contract energy management, personalized customization of power products and other aspects to improve the competitiveness of enterprises, so get a firm foothold in the intense competition of electricity market in the future.

Based on the above analysis and through the investigation and screening, this paper determines the impact of the company's core competitiveness of the following four service mechanisms according to Philip Kotler product sub-structure and combined with the actual operation. The index system is shown in the figure 1: 


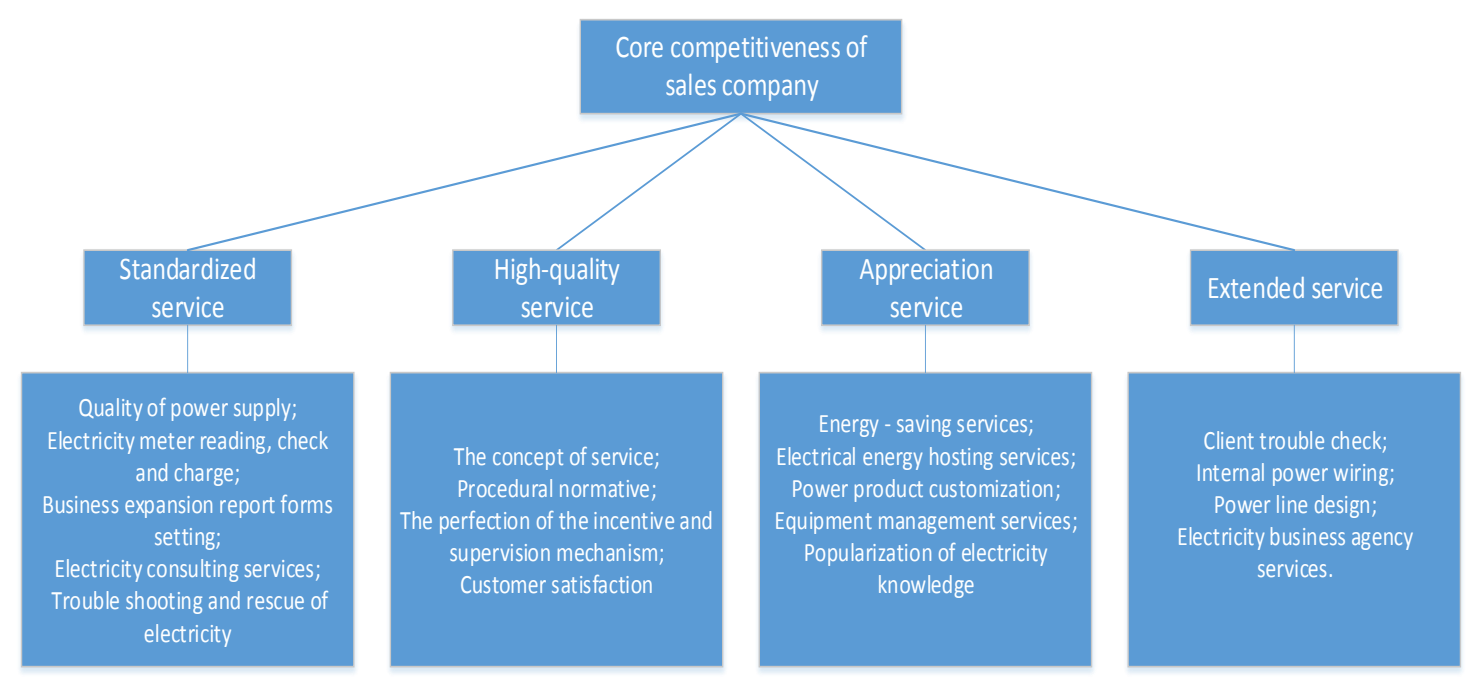

Figure 1. Core competitiveness of sales company

\section{A. Standardized Service}

Standardized service refers to power sales companies provide the most basic services without discrimination and difference in accordance to national laws and policies to protect the basic needs of users. Its content includes the following aspects.

\section{B. Ensure the Quality of Power Supply}

The quality of power supply Include (1) the stability of voltage (2) the safety of power supply (3) the reliability of power supply. Power quality is the most basic indicator that users can intuitively feel the quality of service. Because the quality of power supply often relates to the user's production and life, it firstly determines whether the user will choose a power sales company or not.

\section{Electricity Meter Reading, Check and Charge}

Meter reading timely and accurately not only brings the convenience of management for power sales company and speed up the return of funds, but also enable users to keep abreast of their own electricity information and the situation, and to make adjustments timely to avoid disputes. Accounting accurately is not only related to the company's financial, but also reflects our careful service for customers. Accounting mistakes will lead the users to reduce the reliability for the enterprise even has disputes with them. The timeliness of delivering the payment of electricity cost and the diversification of payment methods save the management costs for the enterprise, and at the same time ,bring convenience for customers, which allow the enterprises to reduce losses while also avoid the users' dissatisfaction due to power outage for arrears.

\section{1) Business Expansion Report Forms Setting}

The user requires the new meter or increasing the electricity consumption owing to the changes in the nature of electricity, the company should organize construction personnel to check the design of user's internal engineering and sign the power supply contract according to the user's request. There are two factors will affect the user's evaluation of the quality of the service----the convenience of the service application process and the timeliness of the business.

\section{2) Electricity Consulting Services}

The power sales company will be consulted when the users lack the knowledge of using electricity and legal policy. The user's service experience can be affected by the diversity of consulting service channels, feedback response speed as well as the accuracy of feedback content. Timely and accurate response will increase the user's trust for the company, and on the contrary, slow response, the errors in reply contents will reduce the user's partiality.

\section{3) Trouble Shooting and Rescue of Electricity}

Trouble shooting and rescue of electricity in standardized service refers to repair power lines and electrical equipment that belong to the power sales company and rapidly restore power supply. Its speed and quality marking the company's ability to deal with emergencies is good or not, and impact the user's evaluation to a certain extent.

\section{High-quality Service}

Providing customers with high quality and efficient service is an effective way to improve the economic efficiency for the power sales company in the power marketing. If companies want to win the race, you must use high quality services in the market to find their own position to obtain long support and preference of customers. Therefore, the power sales companies need to add quality services into its service requirements to accelerate the pace of progress by providing quality power supply services for power users. There are several options can be selected.

Try to change the concept of service, and enhance their sense of responsibility.

Establish a complete marketing service management system, standardize the service procedures, make the power service content transparent, in order to enhance the quality of service and standardize the business procedures. 
Improve the incentive and supervision mechanism. For quality service, perfect incentive and supervision mechanisms are essential. Only the company has an effective internal oversight mechanism, the employee can be aware of their own responsibilities and rights. The incentive mechanism ensures the enthusiasm of the staff.

Divide the customers into several segments according to their own nature, identify the difficulty and difference between the businesses, provide customers with personalized service, and effectively improve the response speed and customer satisfaction to achieve long-term cooperation with customers and the power service changing from the emergency-oriented to the service-oriented.

\section{E. Appreciation Service}

Appreciation service refers to provide customers with beyond the standardized services and high-quality service based on the customer's needs for the purpose of providing customers with safe and reliable power supply and sincere services and improving the customer satisfaction, which will eventually achieve a win-win situation for continuing to create value for customers and bringing short-term or long-term value for the power sales companies. Appreciation services include but are not limited to the followings.

\section{1) Energy-saving Services}

With the continuous reduction of available resources in the worldwide, the prices of all kinds of energies have climbed year by year. Energy saving and low-carbon living are becoming more and more popular among people. But the users are often unable to achieve scientific and effective energy saving for being limited to energy or electricity knowledge. The power sales companies can use their abundant data and information to provide users with energy-saving service. This way saves electricity for users and optimizes the resource allocation for the company at the same time, which achieves the social benefits of Pareto optimal.

\section{2) Electrical Energy Hosting Services}

This type of service is suitable for enterprises with large electricity consumption, which take the charge of all-round management about the purse and use of electricity, the efficiency of energy equipment, energy-using mode and the government energy conservation assessment. They provide customers with energy experts type of value services by the way of supplying funds for technical and equipment updates, and then to achieve energy conservation costs, and get a presentable score in the government energy conservation assessment. Energy hosting includes full hosting and semi-hosting. Full hosting includes equipment operation, management and maintenance, personnel management, environmental compliance control management, daily energy and operating costs, and ultimately to provide energy use to customers. Semi-hosting only includes daily equipment operation, management and maintenance.

\section{3) Power Product Customization}

As the users' demand for electricity are different, the companies should provide standardized services on the basis of the user's own demand for electricity to customize, which includes two aspects: electrical equipment and power quality. Electrical equipment can be different in the form, installation and capacity, while the differences in power quality are reflected in the voltage, time of stopping, whether it is generated by renewable energy. Power sales company can expand their business by working with power equipment manufacturing enterprises or electronic trading supplier platform.

\section{4) Equipment Management Services}

This type of services include (1)Evaluation of electrical equipment characteristics(Through the assessment of electric water heaters, air conditioning, rice cookers and other household appliances electricity characteristics to develop a reasonable use way of electricity for customers.) (2)Equipment energy efficiency assessment services (Analyze the efficiency of the equipment according to the operating parameters of the electrical equipment; evaluate the operation efficiency of the equipment, the unit time power consumption, the sulfur dioxide emissions and the carbon dioxide emissions.) (3)Equipment health assessment services (According to the collection of electrical equipment data information, combined with historical data and online monitoring data, to assess and predict the health of electrical equipment).

\section{5) Popularization of Electricity Knowledge}

Power Sales companies can promote electricity safety knowledge, energy-saving methods, electricity price information and power policy to the users through SMS, website, social media platform, etc. This service not only increases the opportunities of interacting with the user but also is a reflection of the company assuming the social responsibility. Additionally, in this way, companies can make reputation and preference improved at the same time to enhance the competitiveness.

\section{F. Extended Service}

Extension services refer to services that provide customers with solutions to problems within the client's property, which are mostly in the area of property management. Such services will increase the management costs, but will gain the user's favor, enhance the customer sticky and improve the preference of the company at the same time. Enterprises should combine their own situation and needs of users in the provision of extended services, make a perfect balance between income and expenditure to obtain the necessary income without reducing the user s' evaluation for the company. Extended services include but are not limited to the following aspects.

\section{1) Client Trouble Checking}

For security reasons, power users are often unable to exclude the line failure within their own property. Lacking of professional technicians results in it difficult to troubleshoot timely, which affect the quality of customers' lives. Power sales companies can use their own resources or work with power grid enterprises and social technical personnel to help users contact and improve service levels. 


\section{2) Help Connect the Power Wiring within Customer} Belongings

Consistent with the client trouble check, company should give service when requested by the user, and determined the charges to reduce rights disputes.

3) Design of Electric Power Circuit

Companies can train the relevant technical personnel or cooperation with the social organization to design both economic and safe power lines for the user combined with the user needs and electricity consumption structure. The company can use the economies of scale effect to save design costs for the users, expand corporate services, and enrich development potential.

4) Electricity Business Agency Services

The need of such service is due to time and energy constraints. Power sales companies can establish a "customer-parent" mechanism to provide users with related services, which not only can accelerate the speed of the company's business but also bring more users with comfortable, convenient and efficient service experience.

\section{G. The Establishment of the Weight of the Index System}

The traditional hierarchical analysis is based on the 1 9 scale method, and the judgment matrix can be obtained by comparing the evaluation indexes, then we can acquire quantitative conclusion. But there are some indexes that can't be quantified in the evaluation of enterprise's competitiveness and they have a certain degree of relative ambiguity. In order to minimize the subjectivity of the evaluation, some scholars combine the traditional analytic hierarchy process with other evaluation methods, such as interval evaluation, fuzzy comprehensive evaluation and expert decision-making, and they take a consider of a variety of qualitative and quantitative factors, so as to reduce the uncertainty Impact. Therefore, the fuzzy AHP (FAHP) is introduced to improve the expert judgment matrix, and then forms a consistency judgment matrix. Combining the row vectors sum uniform method or the square root method with the eigenvector method to realize the comprehensive evaluation of all kinds of electricity sales companies, and more comprehensive application of enterprise information can quantify the data base. Finally, through experts' evaluation, the results of enterprise competitiveness analysis can be more consistent with its actual situation. The specific steps to apply FAHP to the integrated evaluation of the Sales Company are as follows:

\section{1) Establish Fuzzy Consistent Judgment Matrix}

Fuzzy matrix is a matrix representation of fuzzy relation. $U$ is the set of elements, it means that $U=$ $\left\{a_{1}, a_{2}, \ldots, a_{n}\right\}$ and its fuzzy relation matrix can be expressed as (1):

$$
R=\left(\begin{array}{ccc}
r_{11} & \cdots & r_{1 n} \\
\vdots & \ddots & \vdots \\
r_{n 1} & \cdots & r_{n n}
\end{array}\right)
$$

In there, ${ }^{r}{ }_{i j}$ represents a membership of fuzzy relationship between $a_{i}$ and ${ }^{a_{j}}$ when they are compared to the criteria layer, which refers to the importance of the current comparison indicator relative to the upper level indicator. In addition, $r_{i j}$ also has the meaning of the judgment matrix in the aforementioned analytic hierarchy process. In this case, the value of $r_{i j}$ is from 0 to 1 .

If $R$ is consistent during the determination of the membership between the two elements, when ${ }^{r_{j j}}>0.5$, it is right that

$$
\forall k(k=1,2, \ldots, n), r_{i k}>r_{j k}
$$

$r_{i k}-r_{j k}$ is a measure that $a_{i}$ is relatively important than $a_{j}$,so an absolutely importance measure between $a_{i}$ and $a_{j}$ is as follows:

$$
r_{i j}=r_{i k}-r_{j k}+r_{j j}=r_{i k}-r_{j k}+0.5
$$

2) Determine the Weight of Each Factor by Fuzzy Consistent Judgment Matrix

Assuming that the weight of final $a_{n}$ is ${ }^{W_{n}}$, we can see from the definition of $r_{i j}$ that there's a function between $r_{i j}$ and $W_{n}$, that means $r_{i j}=f\left(W_{i}-W_{j}\right)$, and

$$
\begin{aligned}
& r_{i j}=r_{i k}-r_{j k}+0.5=0.5+a\left(w_{i}-w_{j}\right) \\
& \text { So }
\end{aligned}
$$

$$
\left|W_{i}-w_{j}\right|=\frac{\left|r_{i j}-0.5\right|}{a}
$$

There's a reverse relationship between $a$ and the difference in weight. And we can conduct that the weight of $a_{i}$ is (5):

$$
w_{i}=\frac{2 \sum r_{i k}-1}{n^{2}-n}, i, k=1,2, \ldots, n .
$$

\section{3) Comprehensive Evaluation}

Assume that sales company ${ }^{i}$ gets $X_{i j}$ in evaluation index ${ }^{j}$, and according to the previous inference, we can infer that the competitiveness of sales company $i$ is (6): 


$$
V_{i}=\sum X_{i j} W_{j}, j=1,2, \ldots, m .
$$

\section{AN EXAMPLE OF THE CALCULATION OF THE WEIGHT OF THE INDEXES}

Here we use the fuzzy comprehensive evaluation method to calculate the weight of each index for an example.

TABLE I

WEIGHT OF EACH INDEX

\begin{tabular}{|c|c|c|c|c|}
\hline Second Index & $\begin{array}{l}\text { Weight of } \\
\text { second } \\
\text { index }\end{array}$ & Third Index & $\begin{array}{l}\text { Relative weight } \\
\text { to second index }\end{array}$ & $\begin{array}{l}\text { Comprehensive weight of } \\
\text { third index }\end{array}$ \\
\hline \multirow{5}{*}{$\begin{array}{l}\text { Standardized } \\
\text { service }\end{array}$} & \multirow{5}{*}{0.35} & Quality of power supply & 0.36 & 0.1260 \\
\hline & & $\begin{array}{c}\text { Electricity meter reading, check and } \\
\text { charge }\end{array}$ & 0.24 & 0.0840 \\
\hline & & $\begin{array}{c}\text { Business expansion report forms } \\
\text { setting }\end{array}$ & 0.13 & 0.0455 \\
\hline & & Electricity consulting services & 0.09 & 0.0315 \\
\hline & & $\begin{array}{c}\text { Trouble shooting and rescue of } \\
\text { electricity }\end{array}$ & 0.18 & 0.0630 \\
\hline \multirow{13}{*}{$\begin{array}{l}\text { High-quality } \\
\text { service }\end{array}$} & \multirow{13}{*}{0.28} & The concept of service & 0.24 & 0.0672 \\
\hline & & Procedural normative & 0.21 & 0.0588 \\
\hline & & $\begin{array}{l}\text { The perfection of the incentive and } \\
\text { supervision mechanism }\end{array}$ & 0.26 & 0.0728 \\
\hline & & customer satisfaction & 0.29 & 0.0812 \\
\hline & & Energy - saving services & 0.27 & 0.0405 \\
\hline & & Electrical energy hosting services & 0.24 & 0.0360 \\
\hline & & Power product customization & 0.21 & 0.0315 \\
\hline & & Equipment management services & 0.16 & 0.0240 \\
\hline & & $\begin{array}{l}\text { Popularization of electricity } \\
\text { knowledge }\end{array}$ & 0.12 & 0.0180 \\
\hline & & Client trouble check & 0.21 & 0.0462 \\
\hline & & Internal power wiring & 0.26 & 0.0572 \\
\hline & & Power line design & 0.34 & 0.0748 \\
\hline & & Electricity business agent & 0.19 & 0.0418 \\
\hline
\end{tabular}

1) For the first layer of the index, according to the expert evaluates method to obtain a fuzzy judgment matrix on $\left\{a_{1}, a_{2}, a_{3}, a_{4}\right\}$ as follows:

$$
R=\left[\begin{array}{llll}
0.5 & 0.6 & 0.8 & 0.7 \\
0.4 & 0.5 & 0.6 & 0.8 \\
0.2 & 0.4 & 0.5 & 0.7 \\
0.3 & 0.2 & 0.3 & 0.5
\end{array}\right]
$$

2) According to the consistency condition $r_{i j}=r_{i k}-r_{j k}+0.5$ to adjust $R$, we can get a new fuzzy judgment matrix $R_{\text {new }}$ :

$$
R_{\text {new }}=\left[\begin{array}{llll}
0.5 & 0.6 & 0.8 & 0.7 \\
0.4 & 0.5 & 0.7 & 0.6 \\
0.2 & 0.3 & 0.5 & 0.4 \\
0.3 & 0.4 & 0.6 & 0.5
\end{array}\right]
$$

3) Use the formulation (5), we can get the following results

$$
W_{1}=0.35, w_{2}=0.28, w_{3}=0.15, w_{4}=0.22
$$

4) Use the same way to calculate the second layer indexes' weight; we can get a form as shown in table 1 .

\section{SUMMARY}

Power sales company which has a nature of service, the core of its competitiveness lies in services. From the above calculation results, we can conclude that a sales company's basic task is standardized service, on the basis of original task, it can consistently broaden the scope of services and improve the quality of services with the development of itself and the change of customers need. And then, sales company can choose "High-quality service" as its direction of development. If company want to have a long run and sustainable development, enhance its services' ability is necessary. Finally, we hope this evaluation system can offer a reference when other people want to evaluate such kinds of sales companies or sales company need to evaluate its own competitiveness. 


\section{REFERENCES}

[1] Kang-ren HUANG. Research on Competitive Strategy of Power Sales Company Based on Electric Power System Reform. D. Beijing: North China Electric Power University. 2016. (In Chinese)

[2] Ming ZENG, Su-ping YANG, Peng-ju YANG, Jian TANG, Kuo TIAN.2008. East China Electric Power. (In Chinese)

[3] Yong-xiu HE, Xiao-dong PENG, Zhi-yan LIU, Da-cheng LI, Kang-ren HUANG.2014. Power Demand Side Management. (In Chinese)

[4] Rong CUI. 2014. Technology and Enterprise. (In Chinese)

[5] Li-hua ZHANG. Wen-bin SHI.2011.Intelligence. (In Chinese) 